\title{
Photophysical properties of corrphycenes
}

\author{
Daniel O. Mártire ${ }^{\mathrm{a}, *}$, Pablo Vaveliuk ${ }^{\mathrm{b}}$, Gabriel M. Bilmes ${ }^{\mathrm{b}}$ \\ a Instituto de Investigaciones Fisicoquímicas Teóricas y Aplicadas (INIFTA), Facultad de Ciencias Exactas, \\ Universidad Nacional de La Plata (UNLP), Casilla de Correo 16, sucursal 4, 1900 La Plata, Argentina \\ ${ }^{\mathrm{b}}$ Centro de Investigaciones Opticas-CIOp (CONICET-CIC) and UNLP, Casilla de Correo 124, 1900 La Plata, Argentina
}

Received 21 July 1999; accepted 26 July 1999

\begin{abstract}
The photophysical properties of the $\mathrm{Zn}$ salt of octaethylcorrphycene (compound 1) and the doubly protonated octaethylcorrphycene (compound 2) were determined in benzene solutions. Fluorescence spectra and fluorescence quantum yields of $\Phi F(\mathbf{1})=0.03 \pm 0.02$ and $\Phi F(2)=0.06 \pm 0.02$ were measured. The triplet-triplet absorption spectra were obtained by means of flash-photolysis experiments. The triplet quantum yield values $\Phi T(1)=0.79 \pm$ 0.08 and $\Phi T(2)=0.82 \pm 0.08$ were obtained by using laser-induced optoacoustic spectroscopy. The quantum yield of singlet molecular oxygen generation in air-saturated solutions, $\Phi_{\Delta}(\mathbf{1})=0.55 \pm 0.07$ and $\Phi_{\Delta}(2)=0.38 \pm 0.05$, were also measured using time resolved NIR luminescence. (C) 2000 Elsevier Science B.V. All rights reserved.
\end{abstract}

Keywords: Corrphycenes; Fluorescence; Triplet states; Singlet oxygen

\section{Introduction}

The transfer of electronic energy to molecular oxygen from the triplet states of large molecules leading to formation of singlet molecular oxygen, $\mathrm{O}_{2}\left({ }^{1} \Delta_{\mathrm{g}}\right)$, is of biomedical interest for the initiation of tissue damage in photodynamic therapy of tumors (PDT). Several porphyrins and porphycenes have been found to be appropriate for their use in PDT [1].

* Corresponding author. Tel.: + 54-221-4257430; fax: + 54221-4254642.

E-mail address: dmartire@volta.ing.unlp.edu.ar (D.O. Mártire).
Corrphycenes, molecules with close structural similarity to their isomers, porphyrins and porphycenes, were recently synthesized. Their potential use as sensitizers for PDT requires the knowledge of their photophysical properties. Previous work in this direction indicates that corrphycenes meet a priori criteria to be considered for this purpose [2].

The recent availability of the $\mathrm{Zn}$ salt of octaethylcorrphycene (compound 1) and of the doubly protonated octaethylcorrphycene (compound 2) allows us to study the photophysics of these compounds. In this paper we report the excitedstate properties of molecules $\mathbf{1}$ and 2 , as well as the transfer of electronic energy to molecular oxygen, in benzene solutions (Scheme 1). 


\section{Experimental}

Compounds 1 and 2 were synthesized by the group of Professor Emanuel Vogel (Cologne). Rhodamine B, Zn-tetraphenylporphyrine ( $\mathrm{ZnTPP}$ ) and 2-hydroxy benzophenone were used as supplied from Aldrich. Ethanol and benzene were from Merck.

Ground-state absorption spectra were recorded with a Cary 3 computer-controlled spectrophotometer. Fluorescence emission spectra were recorded on a SLM 4800C Aminco spectrofluorimeter (excitation-wavelength $=355 \mathrm{~nm}$ ), using $\mathrm{N}_{2}$-saturated solutions of matched absorbances $(0.050 \pm 0.002)$ of compounds 1 and 2 in benzene, and the reference rhodamine $B$ in ethanol $\left(\Phi_{\mathrm{f}=0.65)}\right.$ [3]. The comparison of the areas of the complete fluorescence spectra of $\mathbf{1}$ and 2 with that of the reference yielded the $\left(\Phi_{\mathrm{F}}\right.$ values.

\subsection{Triplet measurements by flash photolysis}

Triplet-triplet $(\mathrm{T}-\mathrm{T})$ absorption of compounds 1 and 2 were obtained through flash-photolysis (FP) experiments with optical detection. $\mathrm{N}_{2}$-saturated benzene solutions were excited with the third harmonic $(\lambda=355 \mathrm{~nm})$ of a Nd:YAG laser (Spectron SL 800, 8 ns pulsewidth). The comparative method was employed to determine the product $\Delta \varepsilon_{460} \Phi_{\mathrm{T}}$ (triplet minus ground-state absorption coefficient times intersystem crossing quantum yield) [4]. The dependence of the transient absorbance extrapolated to zero-time $\left(A_{0}\right)$ on the laser energy was determined at $\left(\lambda_{\text {obs }}=460\right.$ $\mathrm{nm}$ for $\mathbf{1}$ and $\mathbf{2}$ and the reference ZnTPP

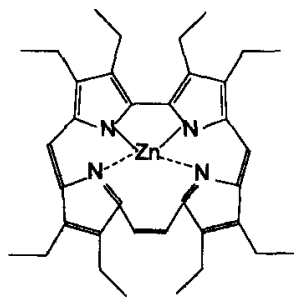

Compound 1

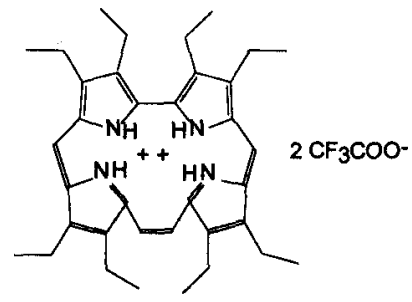

Compound 2
$\left(\Delta \Phi_{460 \mathrm{~T}}=6.2 \times 10^{4} \mathrm{M}^{-1} \mathrm{~cm}^{-1}\right)[5,6]$. The absorbance of sample and reference solutions at the excitation wavelength $\left(A_{355}=0.150\right)$ were matched within \pm 0.002 .

\subsection{LIOAS experiments}

Laser induced optoacoustic spectroscopy (LIOAS) was used for the determination of the product $\Phi_{\mathrm{T}} E_{\mathrm{T}}$. The excitation source was the third harmonic of a Nd:YAG laser (Surelite II, Continuum, $7 \mathrm{~ns}$ fwhm pulse). The pressure wave was monitored with a piezoelectric ceramic detector characterized by a resolution time of $1 \mu \mathrm{s}$ [7]. The excitation energy was attenuated using two polarizers and measured with a pyroelectric detector (RjP-76, Laser Precision) using a calibrated quartz glass as beam-splitter. All experiments were carried out in the linear-energy-dependent range. The amplitude of the acoustic signal $(H)$ was used to determine the prompt heat response of the system. The amplified acoustic signals were processed and stored by a digital oscilloscope (TDS 540, Tektronix). 2-Hydroxybenzophenone (2HOB) was used as the calorimetric reference [8]. All the experiments were performed in $\mathrm{N}_{2}$-saturated solutions, at absorbances in the range 0.08 0.20 .

\subsection{Time-resolved NIR luminescence}

Quantum yields of singlet molecular oxygen $\left[\mathrm{O}_{2}\left({ }^{1} \Delta_{\mathrm{g}}\right)\right]$ generation $\left(\Phi_{\Delta}\right.$, were determined using time-resolved near infrared luminescence with the same excitation as described above for LIOAS.

The luminescence emerging from the cuvette passed through a filter combination (a cut-off at $1050 \mathrm{~nm}$ plus an interference filter at $1270 \pm 50$ $\mathrm{nm}$ ) and was collected with a germanium diode (Judson $1168 \mathrm{Sp}, 5 \mathrm{~mm}$ diameter) placed at a right angle to the excitation beam. The signals were stored in a PC and the decays fitted with a single-exponential decay function.

In order to obtain $\Phi_{\Delta}$, the phosphorescence amplitude extrapolated to zero time $\left(I_{0}\right)$ (determined at various laser pulse energies, $\left.E_{\text {las }}\right)$ was compared to the value of the energy-dependent $I_{0}$ value for anthracene ( $\Phi_{\Delta}=0.66$ in benzene) [9] 


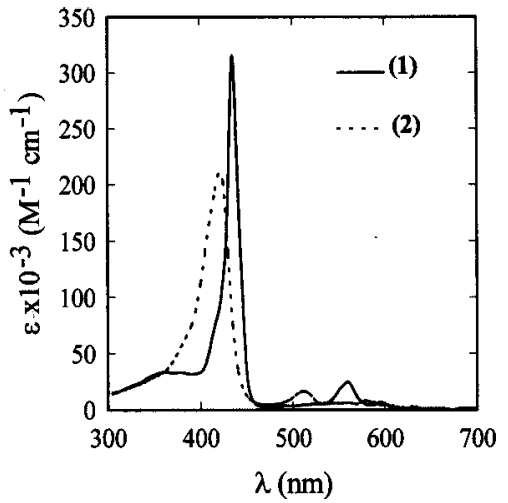

Fig. 1. UV-visible absorption spectra of compounds $\mathbf{1}$ and $\mathbf{2}$ in benzene. The value of the absorption maxima and the absorption coefficients are: $435 \mathrm{~nm}\left(\varepsilon=315 \times 10^{3} \mathrm{M}^{-1} \mathrm{~cm}^{-1}\right) ; 560$ $\mathrm{nm}\left(\varepsilon=25 \times 10^{3} \mathrm{M}^{-1} \mathrm{~cm}^{-1}\right) ; 596 \mathrm{~nm}\left(\varepsilon=6.8 \times 10^{3} \mathrm{M}^{-1}\right.$ $\left.\mathrm{cm}^{-1}\right)$ for compound 1 ; and $423 \mathrm{~nm}\left(\varepsilon=210 \times 10^{3} \mathrm{M}^{-1}\right.$ $\left.\mathrm{cm}^{-1}\right) ; 512 \mathrm{~nm}\left(\varepsilon=16.5 \times 10^{3} \mathrm{M}^{-1} \mathrm{~cm}^{-1}\right) ; 561 \mathrm{~nm}(\varepsilon=$ $\left.6.2 \times 10^{3} \mathrm{M}^{-1} \mathrm{~cm}^{-1}\right) ; 577 \mathrm{~nm}\left(\varepsilon=7.9 \times 10^{3} \mathrm{M}^{-1} \mathrm{~cm}^{-1}\right)$ and $632 \mathrm{~nm}\left(\varepsilon=2.9 \times 10^{3} \mathrm{M}^{-1} \mathrm{~cm}^{-1}\right)$ for compound 2 .

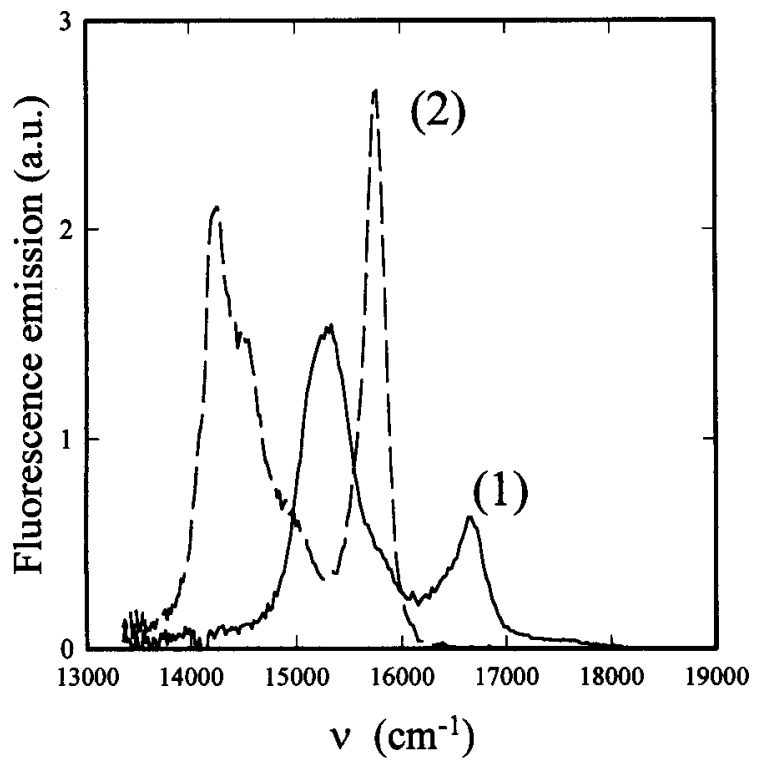

Fig. 2. Emission spectra of $\mathrm{N}_{2}$-saturated benzene solutions of: $1.5 \mu \mathrm{M}$ compound 1 and $1.6 \mu \mathrm{M}$ compound $2 . \lambda_{\text {exc }}=355 \mathrm{~nm}$. The emission maxima are 652 and $634 \mathrm{~nm}$ for compounds 1 and 2 , respectively.

used as the reference. Comparison of the slopes of the linear plots $I_{\mathrm{o}}$ versus $E_{\text {las }}$ of solutions of sample and reference under the same conditions (i.e. air-saturated solutions of matched absorbances in the same solvent; $A_{355}=0.5$ ) afforded the ( $\Phi_{\Delta}$ values).

\section{Results}

\subsection{Ground-state absorption and fluorescence spectroscopy}

The UV-visible ground-state absorption and the emission spectra of compounds $\mathbf{1}$ and $\mathbf{2}$ in benzene are shown in (Figs. 1 and 2), respectively.

\subsection{Triplet-state properties}

The $\mathrm{T}-\mathrm{T}$ absorption spectra of compounds 1 and 2 (Fig. 3) show a maximum at $460 \mathrm{~nm}$. The decay of the $460 \mathrm{~nm}$ transient absorbance was in each case monoexponential with $\tau_{\mathrm{T}=}(54 \pm 3) \mu \mathrm{s}$ and $(14 \pm 2) \mu s$, for compounds 1 and 2 , respectively.(Fig. 3)

The zero-time absorbances at the wavelength of the $\mathrm{T}-\mathrm{T}$ absorption maximum of $\mathrm{ZnTPP}, \mathbf{1}$ and 2, were linear functions of the laser-pulse energy, $E_{\text {las. }}$. Using the literature data for ZnTPP (vide supra) the slopes of the straight lines (Fig. 3),

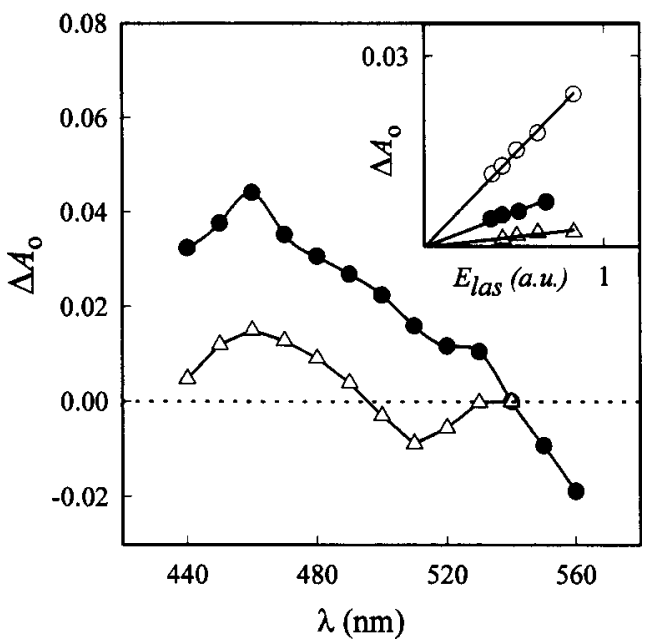

Fig. 3. Triplet-triplet absorption spectra of compound $1(\triangle)$ and compound $2(\Theta)$. Inset: laser energy dependence of the zero-time transient absorbance for compound $1(\triangle)$, compound $2(O)$, and for reference compound $\mathrm{ZnTPP}(\mathrm{O})$. 


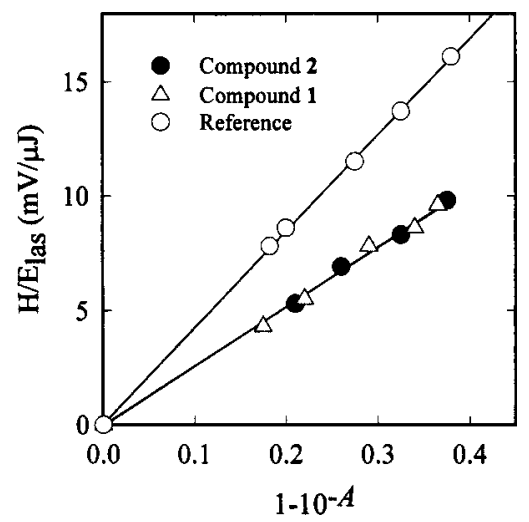

Fig. 4. Ratio $H / E_{\text {las }}$ versus $\left(1-10^{-A}\right)$ for the reference and for compounds 1 and 2 , as indicated.

inset yielded the values $\Delta_{\varepsilon 460} \Phi_{\mathrm{T}}=(2.7 \pm 0.2) \times$ $10^{4}$ and $(10 \pm 1) \times 10^{3} \mathrm{M}^{-1} \mathrm{~cm}^{-1}$ for 1 and 2 , respectively.

Estimated values of $\Delta_{\varepsilon 460}$ for compounds 1 and 2 were determined by using the bleaching at 560 and $510 \mathrm{~nm}$, respectively, and assuming that the triplet-states do not absorb at this wavelength (bleaching region, see Fig. 3). Bleaching recovery measurements at wavelengths closer to the maximum of the Soret bands were precluded due to self-absorption of the analysing beam. The comparison of the slopes of the linear plots of $\left(A_{0}\right.$ vs $E_{\text {las }}$ at 460 and $560 \mathrm{~nm}$ along with the products $\Delta \varepsilon_{460} \Phi_{T}$ afford the value of $\Phi_{T}=(0.46 \pm 0.05)$ for

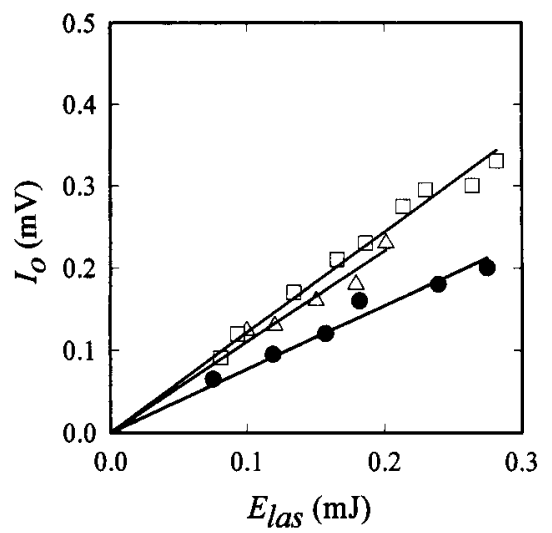

Fig. 5. Laser energy dependence of the extrapolated zero-time amplitude for the time-resolved $\mathrm{O}_{2}\left({ }^{1} \Delta_{\mathrm{g}}\right)$ phosphorescence signal for: anthracene $(\square)$, compound $\mathbf{1}(\triangle)$.
1 and $(0.44 \pm 0.05)$ for 2 . Should the triplet-states of 1 and 2 absorb at 560 and $510 \mathrm{~nm}$, respectively, then the $T$ values would be lower limits.

For transients living longer than the LIOAS experimental window (which is the case of the triplet-states since their lifetime was $>10 \mu$ s for both compounds), the amplitude $(H)$ of the first LIOAS signal deflection is related to the laser energy, $E_{\text {las }}$, and to $A$ by Eq. (1) [8].

$H=k \alpha E_{\text {las }}\left(1-10^{-A}\right)$

in which $k$ is a proportionality constant involving geometrical parameters and thermoelastic properties of the solvent, and (is the fraction of absorbed energy dissipated as heat within the integration time of the experiment. At different absorbances linear plots of $H$ versus $E_{\text {las }}$ were obtained for $\mathrm{N}_{2}$-saturated benzene solutions of compounds $\mathbf{1}$, 2 , and 2-HOB. The ratio of the slopes of the straight lines obtained for $H / E_{\text {las }}$ versus $\left(1-10^{-A}\right)$ (Fig. 4), fields the same value of $\alpha=0.62 \pm 0.02$ for both compounds. This value is used for the calculation of the energy stored by the tripletstates (vide infra).

\section{3. $\mathrm{O}_{2}\left({ }^{1} \Delta_{g}\right)$ generation}

The $\mathrm{O}_{2}\left({ }^{1} \Delta_{\mathrm{g}}\right)$ lifetime in benzene was $\tau_{\Delta}=32 \pm 4$ $\mu$ when using anthracene as sensitizer in excellent agreement with the reported lifetime in this solvent [9]. The same value, within experimental error, was obtained for compounds $\mathbf{1}$ and $\mathbf{2}$ as sensitizers. From the slopes of the energy-dependent zero-time emission amplitudes (Fig. 5) and the literature data for anthracene $\Phi_{\Delta}=0.61 \pm$ 0.07 , the values of $\Phi_{\Delta}=0.55 \pm 0.07$ and $0.38 \pm$ 0.05 are obtained for compounds $\mathbf{1}$ and $\mathbf{2}$, respectively (Table 1 ).

\section{Discussion}

On account of the heavy atomic effect of $\mathrm{Zn}$ in compound 1, a $\Phi_{\mathrm{F}}$ value lower than that obtained for the neutral octaethylcorrphycene [2] should be expected. However, the large error bars involved with the measurement of low fluorescence quantum yields (Table 1) precluded an accurate comparison. 
We here observe monoexponential decays of the triplet-states of compounds 1 and 2 in benzene. However, a biexponential decay was reported [2] for the triplet-states of the neutral octaethylcorrphycene in toluene. Hydrogen abstraction from the methyl group of toluene could account for this discrepancy.

The $\Phi_{\mathrm{T}}$ values obtained by FP for compounds 1 and 2 under the assumption that the triplet-states do not absorb in the bleaching region (vide supra) are lower than those obtained for $\Phi_{\Delta}$. This behaviour could arise from $\mathrm{O}_{2}\left({ }^{1} \Delta_{\mathrm{g}}\right)$ generation through fluorescence quenching by $\mathrm{O}_{2}\left({ }^{3} \Sigma_{\mathrm{g}^{-}}\right)$, which is produced only if the energy gap between the singlet and triplet-states, $E_{S-T}>E$ (the energy content of singlet molecular oxygen $=92 \mathrm{~kJ}$ $\mathrm{mol}^{-1}$ ) [10].

The excited singlet level of compounds $\mathbf{1}$ and $\mathbf{2}$ ( $E_{S}=191 \mathrm{~kJ} \mathrm{~mol}^{-1}$ for both compounds) was determined from the crossing of the absorption and fiuorescence spectra. The triplet-state content of the neutral octaethylcorrphycene molecule in iodopropane was estimated to be about $149 \mathrm{~kJ}$ $\mathrm{mol}^{-1}$ [2]. By taking a similar value of $E_{\mathrm{T}}$ for compounds 1 and 2 (a reasonable assumption in view of the structural similarity of the compounds), the energy gap $E_{S-T}$ would be about 42 $\mathrm{kJ} \mathrm{mol}{ }^{-1}<E$ and the fluorescence quenching by $\mathrm{O}_{2}\left({ }^{3} \Sigma_{\mathrm{g}-}\right)$ leading to $\mathrm{O}_{2}\left({ }^{1} \Delta_{\mathrm{g}}\right)$ should be discarded. In that case, the $\Phi_{\mathrm{T}}$ values obtained by FP should be taken as lower limits due to possible triplet absorption in the bleaching recovery region and the more reliable values of $\Phi_{\mathrm{T}}$ obtained from the LIOAS data should be used [11].

Table 1

Photophysical properties of compounds $\mathbf{1}$ and $\mathbf{2}$

Compound 1

Compound 2

\begin{tabular}{lcc}
\hline$E_{s}\left(\mathrm{~kJ} \mathrm{~mol}^{-1}\right)^{\mathrm{a}}$ & $191 \pm 9$ & $191 \pm 9$ \\
$\Phi_{\mathrm{F}}^{\mathrm{b}}$ & $0.03 \pm 0.02$ & $0.06 \pm 0.02$ \\
$\Phi_{\mathrm{T}}{ }^{\mathrm{c}}$ & $0.79 \pm 0.08$ & $0.82 \pm 0.08$ \\
$\Phi_{\Delta}$ & $0.55 \pm 0.07$ & $0.38 \pm 0.05$
\end{tabular}

a Determined from the crossing of the absorption and emission spectra.

${ }^{b}$ Measured in $\mathrm{N}_{2}$-saturated solutions.

${ }^{c}$ Estimated value from LIOAS experiments assuming for $E_{\mathrm{T}}$ the value determined for the neutral corphycene [2].
The energy balance Eq. (2) was used to evaluate $\Phi_{\mathrm{T}}$ :

$E_{\text {exc }}(1-\alpha)=\Phi_{\mathrm{f}}\left(E_{\mathrm{f}}\right)+\Phi_{\mathrm{T}} E_{\mathrm{T}}$

where $E_{\mathrm{exc}}$ is the excitation energy per mole of photons and $\left(E_{\mathrm{f}}\right)$ is the mean fluorescence energy. By using the values of $\alpha$ and $\Phi_{\mathrm{f}}\left(E_{\mathrm{f}}\right)$ determined in this work, it is obtained $\Phi_{\mathrm{T}} E_{\mathrm{T}}=(117 \pm 7) \mathrm{kJ}$ $\mathrm{mol}^{-1}$ and $\Phi_{\mathrm{T}} E_{\mathrm{T}}=(122 \pm 2) \mathrm{kJ} \mathrm{mol}^{-1}$ for compounds 1 and 2 , respectively. With $E_{\mathrm{T}}=149 \mathrm{~kJ}$ $\mathrm{mol}^{-1}$ as for the neutral octaethylcorrphycene [2], triplet yields of $0.79 \pm 0.08$ and $0.82 \pm 0.08$, respectively, are obtained. These values are close to that determined for the neutral octaethylcorrphycene, as expected from the structural similarity of the three compounds [2]. These results together with the $\phi_{\Delta}$ values, obtained in air-saturated solutions indicate a relatively poor tripletto-oxygen energy transfer process with $S_{\Delta}=\left(=\Phi_{\Delta} / \Phi_{\mathrm{T}}\right)$ values of 0.69 and 0.46 for compounds 1 and 2, respectively. A low $S_{\Delta}$ value is also obtained for the neutral octaethylcorrphycene $\left(S_{\Delta}=0.48 / 0.9=0.53\right)$ [2] in toluene.

The products $\Delta_{\varepsilon 460} \Phi_{\mathrm{T}}=(2.7 \pm 0.2) \times 10^{4}$ and $(10 \pm 1) \times 10^{3} \mathrm{M}^{-1} \mathrm{~cm}^{-1}$ for compounds 1 and 2 , obtained from FP measurements along with the $\Phi_{\mathrm{T}}$ values determined by LIOAS yield $\Delta_{\Phi 460}=$ $(3.4 \pm 0.4) \times 10^{4}$ and $(1.2 \pm 0.2) \times 10^{4} \mathrm{M}^{-1} \mathrm{~cm}^{-1}$ for both compounds, respectively (Table 1 ).

Thus, compounds $\mathbf{1}$ and $\mathbf{2}$ fulfil some of the a priori criteria - under in vitro conditions in liquid solution - given as prerequisites for dyes to qualify as agents suited for photodynamic tumor therapy $[12,13]$.

\section{Acknowledgements}

We thank Professors Silvia E. Braslavsky and Kurt Schaffner for their support and encouragement and Prof. Emmanuel Vogel (University of Cologne) for providing the corrphycenes samples. This research was partially supported by grants number A-13218/1-2048062, A-13359/1-000084 and A-13434/1-000105 of Fundación Antorchas (Argentina), and 2756-1100/94 of Comisión de Investigaciones Cientificas de la Provincia de Buenos Aires (CIC). We thank Drs H. Garda 
(INIBIOL, Argentina) and P.F. Aramendía (INQUIMAE, Argentina) for allowing us the use of the fluorimeter and flash-photolysis set-up, respectively. D.O. Mártire and G.M. Bilmes are members of CIC and UNLP. P. Vaveliuk is fellow of CONICET and member of UNLP.

\section{References}

[1] C.J. Gomer, Photochem. Photobiol. 54 (1991) 1093.

[2] E. Vogel, M. Bröring, S.J. Weghorn, P. Scholz, R. Deponte, J. Lex, H. Schmickler, K. Schaffner, S.E. Braslavsky, M. Müller, S. Pörting, C.J. Fowler, J. Sessler, Angew. Chem. Int. Ed. Engl. 36 (1997) 1651.

[3] I. López Arbeola, K.K. Rohatgi-Mukherjee, Chem. Phys. Lett. 129 (1986) 607.
[4] R.V. Bensasson, C.R. Goldschmidt, E.J. Land, T.G. Truscott, Photochem. Photobiol. 28 (1978) 277.

[5] I. Carmichael, G.L. Hug, J. Phys, Chem. Ref. Data 15 (1986) 183.

[6] L. Pekkarinen, H. Linschitz, J. Am. Chem. Soc. 82 (1960) 2407.

[7] D.H. Murgida, R. Erra-Balsells, G.M. Bilmes, Chem. Phys. Lett. 250 (1996) 198.

[8] S.E. Braslavsky, G.E. Heibel, Chem. Rev. 92 (1992) 1381.

[9] F. Wilkinson, W.P. Helman, A.B. Ross, J. Phys. Chem. Ref. Data 22 (1993) 113.

[10] A.J. McLean, D.J. McGarvey, T.G. Truscott, C.R. Lambert, E.J. Land, J. Chem. Soc. 86 (1990) 3075.

[11] S. Nonell, P.F. Aramendía, K. Heihoff, R.M. Negri, S.E. Braslavsky, J. Phys.Chem. 94 (1990) 5879.

[12] H. Van der Bergh, Chem. Br. 22 (1990) 430.

[13] D.O. Mártire, N. Jux, P.F. Aramendía, R.M. Negri, J. Lex, S.E. Braslavsky, K. Schaffner, E. Vogel, J. Am. Chem. Soc. 114 (1992) 9969. 